\title{
QUANTITATIVE INSULIN SENSITIVITY CHECK INDEXES IN EARLY POSTPARTUM COWS AND CALVES KEPT IN A BEEF SUCKLER SYSTEM
}

\author{
L. Vrankovićl, J. Aladrovićl , I. Pipal ${ }^{2}$, B. Beer Ljubić', N. Prvanović Babić, ${ }^{4}$ Z. Stojevićl \\ lana.vrankovic@vef.hr
}

${ }^{1}$ University of Zagreb, Faculty of Veterinary Medicine,

Department of Physiology and Radiobiology,

Heinzelova ul., 55, Zagreb, 10000, Croatia

${ }^{2}$ Veterinary clinic VETMED d.o.o.,

Gornje Selo 59, Stružec, Popovača, 44317, Croatia

${ }^{3}$ University of Zagreb, Faculty of Veterinary Medicine, Internal Diseases Clinic,

Heinzelova ul., 55, Zagreb, 10000, Croatia

${ }^{4}$ University of Zagreb, Faculty of Veterinary Medicine,

Reproduction and Obstetrics Clinic,

Heinzelova ul., 55, Zagreb, 10000, Croatia

The aim of our study was to determine indexes of insulin resistance (IR) in early postpartum period in cows and their calves kept in a beef suckler system. The study was conducted on 13 Simmental cows and their calves. We calculated following indexes values: RQUICKI (Revised Quantitative Insulin Sensitivity Check Index) and its modified version RQUICKI ${ }_{B H B}$, HOMA (Homeostatic Model Assessment) and QUICKI (Quantitative Insulin Sensitivity Check Index) based on serum concentrations of glucose, insulin, NEFA (non esterified fatty acids) and BHB ( $\beta$-hydroxybutyrate), sampled 6, 12 and $48 \mathrm{~h}$ and 7 and $14 \mathrm{~d} \mathrm{pp}$. Cows were grouped according to lactation number ( $2^{\text {nd }}$ to $4^{\text {th }}$ lactation, $1^{\text {st }}$ group; and $5^{\text {th }}$ to $8^{\text {th }}$ lactation, $2^{\text {nd }}$ group) and calves according to gender.

Results showed that RQUICKI was higher in $1^{\text {st }}$ group of cows $(P>0.05)$ and showed progressive increase during pp period in both groups. In $1^{\text {st }}$ group of cows RQUICKI was lower 6 and $12 \mathrm{~h}$ pp than $14 \mathrm{~d}$ p.p. $(P=0.01)$. HOMA was higher in $2^{\text {nd }}$ group of cows $(P>0.05)$; HOMA was higher $12 \mathrm{~h} p p$ than $48 \mathrm{~h}, 7$ and $14 \mathrm{~d} p . p .(P=0.01)$ as well as $6 \mathrm{~h}$ pp than 7 and $14 \mathrm{~d}$ p.p. $(P=0.01)$. QUICKI showed the same trend in both groups, progressive decrease from 6 h to 14 d p.p. $\left(P=0.001,1^{\text {st }}\right.$ group; $P=0.001,2^{\text {nd }}$ group $)$. In calves, HOMA was higher in females $(P>0.05)$. In females HOMA was lower $6 \mathrm{~h}$ pp than 7 and $14 \mathrm{~d}$ p.p. $(P=0.03)$. RQUICKI ${ }_{B H B}$ was higher in females than in males $(P=0.03)$. RQUICKI $I_{B H B}$ showed progressive decline from $6 \mathrm{~h}$ p.p. to $14 \mathrm{~d}$ p.p. in females $(P=0.004)$. Changes in trends of IR indexes may help in analysis of decreased sensitivity or responsiveness to the metabolic actions of insulin as well as in determination of metabolic status of animals.

Keywords: COWS, CALVES, EARLY POSTPARTUM PERIOD, INSULIN RESISTANCE, BEEF SUCKLER SYSTEM

Insulin is a key regulator of glucose homeostasis. Insulin resistance (decreased sensitivity or responsiveness to the metabolic actions of insulin) is determined by both genetic and environmental factors. Insulin resistance is defined as a condition when higher than normal insulin concentrations are needed to achieve normal metabolic responses [9].

In high-yielding postpartum (p.p.) dairy cows insulin resistance (IR) develops to help directing nutrients from insulin sensitive tissues such as skeletal muscle and adipose tissue to the lactating mammary gland and for the growing fetus, as an important homeorhetic adaptation mechanism of mammals [1]. In dairy cows genetically selected for high-milk production, these homeorhetic adaptation mechanisms are driven to extremes. Insulin resistance in the transition period has been associated with several pathological conditions like ketosis, cystic ovarian disease, fatty liver and the fat cow syndrome is a well-known problem [5, $10,12]$. The etiology of IR in veal calves may be complex and multifactorial [7]. It has been shown that a prolonged intake of high levels of milk replacement (large amounts of lactose and fat) may induce problems with glucose homeostasis and insulin sensitivity in heavy veal calves ( $>4$ month old), as characterized by high incidences of hyperglycemia and hyperinsulinemia [7, 8]. These problems may ultimately result in (pro)inflammatory stress and metabolic diseases. 
In humans, surrogate indices for insulin sensitivity have been proposed based on the analysis of glucose, insulin, NEFA (non esterified fatty acids), and BHB ( $\beta$-hydroxybutyrate) in a single blood sample after an overnight fast. The surrogate indices most frequently used are the homeostasis model of IR (HOMA-IR), the quantitative insulin sensitivity check index (QUICKI), and the revised quantitative insulin sensitivity check index (RQUICKI) [11, 13].

In order to prevent the development of IR, it is of importance to understand the patho-physiological mechanisms of IR and to identify early biomarkers of decreased insulin sensitivity.

\section{Materials and methods}

The animals were kept in a beefsuckler system. Most of the year, cows were kept on pasture but during the late autumn/winter period, when all calving took place (November 2012 to March 2013) they were housed in a barn. During the indoor period, whole corn silage, meadow hay (mixed herbs) and a concentrate, based on ground corn, ground soybean and sunflower pellets, were fed to cows twice a day. The calves were kept in separate wooden boxes next to their mothers and were allowed to nurse ad libitum 4 times per day until $14 \mathrm{~d}$ of age. Age of cows ranged from 3.5 to 10.5 y $(6.58 \pm 2.93$; mean $\pm \mathrm{SD})$; lactation number ranged from $2^{\text {nd }}$ to $8^{\text {th }}$. Average milk yield during lactation was $5660 \mathrm{~kg}$. All animals were clinically healthy.

Blood samples were collected from October to March 2013 from each cow and her calf and were taken at 6,12 and $48 \mathrm{~h}$ and 7 and $14 \mathrm{~d}$ after calving. Samples were taken by jugular vein puncture (v. jugularis externa) into test tubes containing gel (BD Vacutainer ${ }^{\circledR}$ tubes, BD Diagnostics, Plymouth, UK). After coagulation and centrifugation $\left(2000 \times \mathrm{g}\right.$ for $20 \mathrm{~min}$, at $+4{ }^{\circ} \mathrm{C}$ ) serum samples were frozen and stored $-20{ }^{\circ} \mathrm{C}$ until analysis. The concentrations of glucose and NEFA (non-esterified fatty acids) were determined by spectrophotometry using a biochemistry analyzer $S A B A 18$ (AMS, Rome, Italy) and reagents (Herbos Diagnostics, Sisak, Croatia). The concentrations of insulin was determined using an immunoenzymometric (IEMA) assay in accordance with the instructions provided by the manufacturers (Insulin Bovine
Elisa, DRG Instruments GmbH, Marburg, Germany). Based on serum concentrations of glucose, insulin, NEFA and BHB we calculated following indexes values: RQUICKI (Revised Quantitative Insulin Sensitivity Check Index) and its modified version RQUICKI ${ }_{\text {BHB }}$, HOMA (Homeostatic Model Assessment) and QUICKI (Quantitative Insulin Sensitivity Check Index).

Cows were grouped according to lactation number $\left(2^{\text {nd }}\right.$ to $4^{\text {th }}$ lactation, $1^{\text {st }}$ group; and $5^{\text {th }}$ to $8^{\text {th }}$ lactation, $2^{\text {nd }}$ group) and calves according to gender. All data were statistically analysed using Statistica version 10 (StatSoft Inc., Tulsa, USA). The results are presented in tables as means and standard deviation (mean $\pm \mathrm{SD}$ ). The significance of differences within the group between the sampling periods using time of sampling as factor was assessed by analysis of variance of repeated measurements and Tukey's test in case of normal distribution while a non-normal distribution was checked by Kruskal-Wallis ANOVA. The level of significance was set at $\mathrm{P} \leq 0.05$.

\section{Results and discussion}

Insulin resistance is a phenomenon that occurs in early lactation in cows and neonatal calves if fed by large amounts of lactose and fat, and is characterised by lower insulin production and lower tissue response to insulin. Results showed that RQUICKI was higher in $1^{\text {st }}$ group of cows $(\mathrm{P}>0.05)$ and showed progressive increase during p.p. period in both groups, which was in accordance with results [6]. Value of RQUICKI index is dependant on the insulin value in dry cows, but on NEFA value in early lactation cows [3]. In $1^{\text {st }}$ group of cows RQUICKI was lower 6 and 12 h p.p. than 14 d p.p. $(\mathrm{P}=0.01)$. Decreased RQUICKI values are in accordance with higher insulin resistance [3, 4]. RQUICKI index, compared to HOMA and QUICKI indexes, is the better predictor of metabolic status [3]. There are scarce reports on the relationship between HOMA values and insulin resistance in cows. HOMA was higher in $2^{\text {nd }}$ group cows $(\mathrm{P}>0.05)$. In $1^{\text {st }}$ group of cows, HOMA was higher 12 h p.p. than 48 h, 7 and 14 d p.p. $(\mathrm{P}=0.01)$. Similarly, in $2^{\text {nd }}$ group of cows HOMA was higher $6 \mathrm{~h}$ p.p. than 7 and 14 d p.p. $(P=0.01)$. [5] and [3] found 
Values of RQUICKI, RQUICKI ${ }_{B H B}$, HOMA and QUICKI in cows in $2^{\text {nd }}-4^{\text {th }}$ and in $5^{\text {th }}-8^{\text {th }}$ lactation during different sampling times

\begin{tabular}{|c|c|c|c|c|c|c|c|}
\hline \multirow{2}{*}{ Parameter } & \multirow{2}{*}{$\mathrm{N}$} & \multicolumn{5}{|c|}{ Sampling time } & \multirow{2}{*}{ P-value } \\
\hline & & $6 \mathrm{~h}^{*}$ & $12 \mathrm{~h}^{*}$ & $48 \mathrm{~h}^{*}$ & $7 d^{*}$ & $14 \mathrm{~d}^{*}$ & \\
\hline \multicolumn{8}{|c|}{$2^{\text {nd }}-4^{\text {th }}$ lactation } \\
\hline RQUICKI & 4 & $0.52 \pm 0.07^{\mathrm{a}}$ & $0.50 \pm 0.05^{\mathrm{a}}$ & $0.76 \pm 0.10^{\mathrm{ab}}$ & $0.74 \pm 0.08^{\mathrm{ab}}$ & $1.17 \pm 0.49^{b}$ & 0.01 \\
\hline RQUICKI $_{\text {BHB }}$ & 4 & $0.64 \pm 0.14^{\mathrm{a}}$ & $0.61 \pm 0.06^{\mathrm{a}}$ & $1.13 \pm 0.16^{\mathrm{a}}$ & $1.11 \pm 0.25^{\mathrm{a}}$ & $7.26 \pm 6.70^{\mathrm{a}}$ & $>0.05$ \\
\hline HOMA & 4 & $3293 \pm 1747^{\mathrm{ab}}$ & $4401 \pm 2901^{\mathrm{a}}$ & $900 \pm 460^{b}$ & $880 \pm 397^{\mathrm{b}}$ & $808 \pm 974^{\mathrm{b}}$ & 0.01 \\
\hline QUICKI & 4 & $2.21 \pm 0.24^{\mathrm{a}}$ & $0.44 \pm 0.06^{\mathrm{b}}$ & $0.61 \pm 0.08^{b}$ & $0.60 \pm 0.06^{\mathrm{b}}$ & $0.75 \pm 0.23^{b}$ & $<0.01$ \\
\hline \multicolumn{8}{|c|}{$5^{\text {th }}-8^{\text {th }}$ lactation } \\
\hline RQUICKI & 5 & $0.53 \pm 0.15^{\mathrm{a}}$ & $0.58 \pm 0.17^{\mathrm{a}}$ & $0.59 \pm 0.07^{\mathrm{a}}$ & $0.68 \pm 0.17^{\mathrm{a}}$ & $0.83 \pm 0.13^{\mathrm{a}}$ & $>0.05$ \\
\hline RQUICKI $_{\mathrm{BHB}}$ & 5 & $0.73 \pm 0.27^{\mathrm{a}}$ & $0.77 \pm 0.31^{\mathrm{a}}$ & $0.76 \pm 0.18^{\mathrm{a}}$ & $0.96 \pm 0.47^{\mathrm{a}}$ & $1.01 \pm 0.19^{\mathrm{a}}$ & $>0.05$ \\
\hline HOMA & 5 & $4932 \pm 4932^{\mathrm{ac}}$ & $3962 \pm 3849^{c}$ & $2289 \pm 1727^{\text {bc }}$ & $888 \pm 315^{\text {bc }}$ & $730 \pm 99^{b}$ & 0.01 \\
\hline QUICKI & 5 & $2.20 \pm 0.53^{\mathrm{a}}$ & $0.47 \pm 0.08^{a}$ & $0.51 \pm 0.07^{b}$ & $0.61 \pm 0.08^{b}$ & $0.62 \pm 0.02^{\mathrm{b}}$ & $<0.01$ \\
\hline
\end{tabular}

Note: ${ }^{\mathrm{a}, \mathrm{b}, \mathrm{c}}$ - different superscripts in the same row shows significant difference within the group $(\mathrm{P}<0.05) ;{ }^{*}-$ hours/days postpartum; results presented as mean $\pm \mathrm{SE}$; NS — non significant.

Values of RQUICKI, RHUICKI ${ }_{\mathrm{BHB}}$, HOMA and QUICKI in female and male calves

Table 2 during different sampling times

\begin{tabular}{|c|c|c|c|c|c|c|c|}
\hline \multirow{2}{*}{ Parameter } & \multirow{2}{*}{$\mathrm{N}$} & \multicolumn{5}{|c|}{ Sampling time } & \multirow{2}{*}{ P-value } \\
\hline & & $6 \mathrm{~h}^{*}$ & $12 \mathrm{~h}^{*}$ & $48 \mathrm{~h}^{*}$ & $7 d^{*}$ & $14 \mathrm{~d}^{*}$ & \\
\hline \multicolumn{8}{|c|}{ Female calves } \\
\hline RQUICKI & 4 & $0.52 \pm 0.11^{\mathrm{a}}$ & $0.50 \pm 0.08^{\mathrm{a}}$ & $0.50 \pm 0.09^{a}$ & $0.54 \pm 0.11^{\mathrm{a}}$ & $0.43 \pm 0.10^{\mathrm{a}}$ & $>0.05$ \\
\hline RQUICKI $_{\mathrm{BHB}}$ & 4 & $3.94 \pm 4.34^{\mathrm{aA}}$ & $1.72 \pm 1.08^{\mathrm{b}}$ & $1.05 \pm 0.56^{\mathrm{b}}$ & $1.70 \pm 1.19^{b}$ & $1.07 \pm 0.15^{\mathrm{b}}$ & $<0.01$ \\
\hline HOMA & 4 & $2474 \pm 1805^{\mathrm{a}}$ & $1950 \pm 1241^{\mathrm{a}}$ & $4800 \pm 5106^{\mathrm{a}}$ & $5317 \pm 4913^{b}$ & $5696 \pm 4009^{b}$ & 0.03 \\
\hline QUICKI & 4 & $0.51 \pm 0.12^{\mathrm{a}}$ & $0.52 \pm 0.09^{\mathrm{a}}$ & $0.48 \pm 0.11^{\mathrm{a}}$ & $0.46 \pm 0.12^{\mathrm{a}}$ & $0.43 \pm 0.08^{\mathrm{a}}$ & $>0.05$ \\
\hline \multicolumn{8}{|c|}{ Male calves } \\
\hline RQUICKI & 5 & $0.50 \pm 0.08^{\mathrm{a}}$ & $0.43 \pm 0.05^{\mathrm{a}}$ & $0.56 \pm 0.08^{a}$ & $0.58 \pm 0.10^{\mathrm{a}}$ & $0.51 \pm 0.09^{\mathrm{a}}$ & $>0.05$ \\
\hline RQUICKI $_{\mathrm{BHB}}$ & 5 & $1.42 \pm 0.84^{\mathrm{aB}}$ & $0.89 \pm 0.16^{\mathrm{b}}$ & $5.22 \pm 3.59^{b}$ & $0.74 \pm 1.80^{\mathrm{b}}$ & $1.00 \pm 0.29^{\mathrm{b}}$ & $<0.01$ \\
\hline HOMA & 5 & $2413 \pm 2250^{\mathrm{a}}$ & $5891 \pm 2921^{\mathrm{a}}$ & $2763 \pm 1422^{\mathrm{a}}$ & $2846 \pm 2483^{\mathrm{a}}$ & $5760 \pm 4104^{a}$ & $>0.05$ \\
\hline QUICKI & 5 & $0.53 \pm 0.11^{\mathrm{a}}$ & $0.41 \pm 0.04^{\mathrm{a}}$ & $0.48 \pm 0.06^{\mathrm{a}}$ & $0.48 \pm 0.06^{\mathrm{a}}$ & $0.43 \pm 0.08^{\mathrm{a}}$ & $>0.05$ \\
\hline
\end{tabular}

Note: ${ }^{\mathrm{a}, \mathrm{b}, \mathrm{c}}$ different superscripts in the same row shows significant difference within the group $(\mathrm{P}<0.05)$; ${ }^{\mathrm{AB}}-\mathrm{up}-$ percase superscript shows significant difference $(\mathrm{P}<0.05)$ between groups; * — hours/days postpartum; results presented as mean $\pm \mathrm{SE}$; NS — non significant.

lower HOMA values than were established in our study. Insulin resistant individuals will have increased HOMA values [4]. Countrary, values in our study showed decresing trend. QUICKI showed the same trend in both groups, progressive decrease from $6 \mathrm{~h}$ to $14 \mathrm{~d}$ p.p. $(\mathrm{P}=0.001$, $1^{\text {st }}$ group; $\mathrm{P}=0.001,2^{\text {nd }}$ group). Results by [4] and [3] showed lower QUICKI values than were found in our study. There is insufficient data on QUICKI values in dairy cows. RQUICKI ${ }_{B H B}$ showed no significant differences in our study.

In calves, results for insulin sensitive check indexes are scarce. RQUICKI showed no significant differences. HOMA was higher in females $(\mathrm{P}>0.05)$ than in male calves. In females
HOMA was lower 6 h p.p. than 7 and 14 d p.p. $(\mathrm{P}=0.03)$. QUICKI showed no significant differences, but values in our study were in accordance with the results obtained by [2]. RQUICKI ${ }_{\mathrm{BHB}}$ was higher in females than in males 6 h p.p. $(\mathrm{P}=0.03)$. RQUICKI $_{\mathrm{BHB}}$ showed progressive decline from 6 h p.p. to 14 d p.p. in females $(\mathrm{P}=0.004)$.

\section{Conclusions}

Accoridng to decreased values of QUICKI in both cows and calves, higher insulin resistance can be proposed. Results in cows also showed increased RQUICKI and decreased HOMA what can be found in insulin non-resistant individuals. 
Results in female calves showed RQUICKI decrease while both calves groups showed incresed HOMA values, what can be linked to higher insulin resistance. Reduced insulin sensitivity was shown in the examined population, meaning that insulin resistance is present in the population.

1. Bell A.W. Regulation of organic nutrient metabolism during transition from late pregnancy to early lactation. Journal of Animal Science, 1995, vol. 73, issue 9, pp. 2804-2819. DOI: 10.2527/1995.7392804x.

2. Bossaert P., Leroy J. L. M. R., De Campeneere S., De Vliegher S., Opsomer G. Differences in the glucose-induced insulin response and the peripheral insulin responsiveness between neonatal calves of the Belgian Blue, Holstein-Friesian, and East Flemish breeds. Journal of Diary Science, 2009, vol. 92, issue 9, pp. 4404-4411. DOI: 10.3168/jds.2009-2218.

3. Cincović M., Kirovski D., Vujanac I., Belić B., Djoković R. Relationship between the indexes of insulin resistance and metabolic status in dairy cows during early lactation. Acta Veterinaria-Beograd, 2017, vol. 67, issue 1, pp. 57-70. DOI: 10.1515/acve-2017-0006.

4. De Koster J., Hostens M., Hermans K., Van den Broeck W., Opsomer G. Validation of different measures of insulin sensitivity of glucose metabolism in dairy cows using the hyperinsulinemic euglycemic clamp test as the gold standard. Domestic Animal Endocrinology, 2016, vol. 57, pp. 117-126. DOI: 10.1016/j.domaniend.2016.06.004.

5. Haarstrich D. Evaluation of surrogate indices of insulin sensitivity by means of hyperinsulinemiceuglycemic glucose clamps in dairy cows. In: Insulinsensitivität und Insulinresponse nach einer Langzeit-Supplementation von konjugierten Linolsäuren bei laktierenden Milchkühen. Inaugural disertation. Tierärztliche Hochschule Hannover, 2011.

6. Holtenius P., Holtenius K. A model to estimate insulin sensitivity in dairy cows. Acta Veterinaria Scandinavica, 2007, vol. 49, p. 29. DOI: 10.1186/1751-0147-49-29.
7. Hostettler-Allen R. L., Tappy L., Blum J. W. Insulin resistance, hyperglycemia, and glucosuria in intensively milk-fed calves. Journal of Animal Science, 1994, vol. 72, issue 1, pp. 160-173. DOI: 10.2527/1994.721160x.

8. Hugi D., Bruckmaier R. M., Blum J. W. Insulin resistance, hyperglycemia, glucosuria, and galactosuria in intensively milk-fed calves: Dependency on age and effects of high lactose intake. Journal of Animal Science, 1997, vol. 75, issue 2, pp. 469-482. DOI: $10.2527 / 1997.752469 x$.

9. Kahn C. R. Insulin resistance, insulin insensitivity, and insulin unresponsiveness: a necessary distinction. Metabolism - Clinical and Experimental, 1978, vol. 27, issue 12, suppl. 2, pp. 1893-1902. DOI: 10.1016/S0026-0495(78)80007-9.

10. Kerestes M., Faigl V., Kulcsár A., Balogh O., Földi J., Fébel H., Chilliard Y., Huszenicza G. Periparturient insulin secretion and whole-body insulin responsiveness in dairy cows showing various forms of ketone pattern with or without puerperal metritis. Domesict Animal Endocrinology, 2009, vol. 37, issue 4, pp. 250-261. DOI: 10.1016/j.domaniend.2009.07.003.

11. Muniyappa R., Lee S., Chen H., Quon M. J. Current approaches for assessing insulin sensitivity and resistance in vivo: advantages, limitations, and appropriate usage. American Journal of Physiology, Endocrinology and Metabolism, 2008, vol. 294, issue 1, pp. E15-E26. DOI: 10.1152/ajpendo.00645.2007.

12. Opsomer G., Wensing T., Laevens H., Coryn M., Kruif de A. Insulin resistance: the link between metabolic disorders and cystic ovarian disease in high yielding dairy cows? Animal Reproduction Science, 1999, vol. 56, issue 3-4, pp. 211-222. DOI: 10.1016/ S0378-4320(99)00048-2.

13. Perseghin G., Caumo A., Caloni M., Testolin G., Luzi L. Incorporation of the fasting plasma FFA concentration into QUICKI improves its association with insulin sensitivity in nonobese individuals. Journal of Clinical Endocrinology \& Metabolism, 2001, vol. 86, issue 10, pp. 4776-4781. DOI: 10.1210/jcem.86.10.7902. 